\title{
Increased level of malondialdehyde in preterm labor
}

\author{
Yesi Mustika Sari ${ }^{1 *}$, Eti Yerizel ${ }^{2}$ \\ ${ }^{1}$ Faculty of Health Sciences, Universitas Adiwangsa, Jambi, Indonesia \\ ${ }^{2}$ Faculty of Medicine, Andalas University, Padang, West Sumatera, Indonesia \\ *Corresponding author: Jl. Sersan Muslim No. 16, Thehok, Jambi, Universitas Adiwangsa, Indonesia, 36138. \\ Email: yesi.mustikasari@gmail.com
}

\begin{abstract}
Background: The pathophysiological mechanism associated with spontaneous preterm delivery is oxidative stress through the increased formation of reactive oxygen species (ROS) due to lipid peroxidation. Malondialdehyde (MDA) is one of the biomarkers of oxidative stress produced through the lipid peroxidation process.

Objective: The aim of this study is to observe the difference in MDA levels among preterm labor compared to full-term labor.

Methods: Observational research was conducted with a comparative cross-sectional design. Maternal venous blood samples were taken from private hospitals and midwives in Padang city and Aro Suka Hospital Solok Regency. Samples were selected by consecutive sampling and divided into two groups with a total of 40 samples. MDA level was measured using the spectrophotometry method.

Results: MDA levels in preterm delivery were $3.6 \pm 0.42 \mathrm{nmol} / \mathrm{mL}$ and in full-term delivery were $2.9 \pm 0.33 \mathrm{nmol} /$ $\mathrm{mL}(\mathrm{p}<0.05)$.

Conclusion: There was a significant difference in MDA levels between preterm labor and full-term delivery. MDA levels in preterm childbirth were higher than MDA levels in full-term delivery.
\end{abstract}

Keywords: full-term labor, malondialdehyde, preterm labor

\section{Introduction}

In worldwide, prematurity is the leading cause of death in children under the age of 5 years [1]. In Indonesia, according to Basic Health Research 2007, preterm childbirth was the cause of death in neonates 0-6 days (rank 2) with the number of cases of $32.4 \%$ and cause of neonatal death age 7-28 days (rank 5). Whereas there is no data on preterm childbirth cases for the national level, the incidence of low birth weight (LBW) can describe cases of preterm labor roughly. The prevalence of LBW is $10.2 \%$ and contribute to $60-80 \%$ of newborn death. More than $79 \%$ of babies born at 23-24 weeks gestation have brain abnormalities [2].

Spontaneous childbirth (with intact fetal membranes or premature rupture of amniotic fluid) is caused by infection (intrauterine or extra uterus), inflammation, multiple pregnancies, maternal hormone disorders, and placental abruption. Generally, predisposing factors to preterm childbirth are chronic conditions such as diabetes mellitus and hypertension. Although many of the underlying causes of preterm birth are still unknown, it has been predicted that $40 \%$ of spontaneous preterm labor is caused by intrauterine infections $[3,4]$.

Infection or inflammation of the amniotic fluid is recognized as the main factor causing premature birth. Normally, amniotic fluid is sterile, but more than $1 \%$ of pregnant women who are not in the process of childbirth tend to have a bacterial infection of their amniotic fluid [5]. However, evidence suggests that the motherfetal membrane and amniotic fluid are not always sterile in pregnant women [6]. The occurrence of 
infection in any part of the female reproductive tract during pregnancy is very important because it can trigger strong uterine activity prematurely that leads to premature birth [7].

Malondialdehyde (MDA) is a reactive aldehyde as the final result of the fat peroxidation process due to increased levels of reactive oxygen species (ROS) [8-10]. ROS is generally formed as a result of the metabolism of cells in the body in small amounts but causes harmful effects in excessive amounts $[11,12]$. This compound then reacts with the lipid membrane of the cell which becomes one of the targets prone to being damaged by ROS and produces harmful compounds including MDA $[9,11,12]$. In addition, MDA can also be useful as an indicator to assess oxidative damage because it is produced through the peroxidation of polyunsaturated fatty acid membranes by free radicals $[13,14]$.

During pregnancy, most placentas are rich in mitochondria that favor oxidative stress. Plasma MDA levels are increased as the result of increased lipid peroxidation in placental tissue. Placental lipid peroxide production is abnormally increased in preeclampsia, which is a risk factor for preterm delivery. MDA is accepted as an indirect marker of lipid peroxidation and the increased levels of MDA were found to be the result of increased lipid peroxidation in placental tissue during pregnancy [15].

Many studies reported the effect of oxidative stress on increasing blood pressure both before and during pregnancy; however, oxidative stress status during pregnancy has not been studied before, especially in preterm pregnancy. Therefore, we conducted a study to look at the increase in MDA in preterm labor by comparing MDA levels in term labor.

\section{Methods}

\section{Subjects}

This study was analytical research with a crosssectional method. Laboring mother's blood sample was collected on the diagnosis of preterm and full-term childbirth. The study was conducted in several hospitals and private practice midwives.
These locations include the Reksodiwiryo Padang Hospital, Bhayangkara Hospital, DR. Rasidin Hospital, and several maternity clinics in Padang City and Aro Suka Hospital Solok Regency.

Inclusion criteria were women who gave birth to premature babies with a gestational age of 28 -37 weeks, women who gave birth to babies fullterm with a gestational age of 37 - 41 weeks, with criteria: entering the first stage of the active phase, cervical dilatation $4 \mathrm{~cm}$, uterine contractions 3 times in 10 minutes. Sampling in this study was conducted consecutively. Blood collection was carried out by a trained medical laboratory staff. The patients were fully informed, and they were all asked to sign a written informed consent form. The project was approved by the Research Ethics Committee of the Faculty of Medicine Andalas University, Padang (No. 150/KEP/FK/2019, dated 03 May 2019).

\section{MDA level measurement}

Blood samples were obtained from the study population by taking maternal venous blood, then were collected into a tube containing EDTA (ethylenediaminetetraacetic acid). The blood was then centrifuged at a speed of 2000-3000 rpm for 10-15 minutes. Plasma was collected using a micropipette and stored in a refrigerator at $-80^{\circ} \mathrm{C}$ until they were used for the study. MDA level was exmined by using trichloroacetate and thiobarbituric acid. The following protocol was used to carry out the experiment: i) $0.5 \mathrm{~mL}$ of blood was put into a test tube then $0.5 \mathrm{ml}$ of distilled water was added. ii) $2.5 \mathrm{~mL}$ trichloroacetate $5 \%$ was added and mixed using a vortex mixer, then centrifuged for 10 minutes with a speed of 2000 rpm. iii) $1.5 \mathrm{ml}$ of supernatant was taken and put in the tube according to the label. iv) $1 \mathrm{~mL}$ thiobarbituric acid was added and steamed in a water bath until boiling for 30 minutes and waiting for cooling down. v) the absorbance was read with a spectrophotometer at $\lambda 530 \mathrm{~nm}$.

\section{Data analysis}

The GrapPad software 8.0 was used to generate graph and to perform statistical analysis. The 
Table 1. Characteristics of preterm and aterm childbirth respondents

\begin{tabular}{|c|c|c|c|c|}
\hline Characteristic & Categories & $\begin{array}{c}\text { Preterm } \\
\text { n (\%) }\end{array}$ & $\begin{array}{l}\text { Aterm } \\
\mathrm{N}(\%)\end{array}$ & p-value \\
\hline \multirow{2}{*}{ Age } & Risk & $6(30 \%)$ & $1(5 \%)$ & \multirow{2}{*}{0.001} \\
\hline & Not at risk & $14(70 \%)$ & 19 (95\%) & \\
\hline \multirow{2}{*}{ Parity } & Primipara & 7 (35\%) & 14 (70\%) & \multirow{2}{*}{0.027} \\
\hline & Multipara & $13(65 \%)$ & $6(30 \%)$ & \\
\hline \multirow{3}{*}{ Education } & Low & $3(15 \%)$ & $2(10 \%)$ & \multirow{3}{*}{0.55} \\
\hline & Medium & $13(65 \%)$ & 11 (55\%) & \\
\hline & Higher & $4(20 \%)$ & 7 (35\%) & \\
\hline \multirow{2}{*}{ Work } & Yes & 7 (35\%) & $10(50 \%)$ & \multirow{2}{*}{0.33} \\
\hline & No & $13(65 \%)$ & $10(50 \%)$ & \\
\hline \multirow{2}{*}{$\begin{array}{c}\text { Premature rupture of } \\
\text { membranes (PROM) } \\
\text { history }\end{array}$} & Yes & $6(30 \%)$ & 2 (10\%) & \multirow{2}{*}{0.11} \\
\hline & No & $14(70 \%)$ & 18 (90\%) & \\
\hline
\end{tabular}

characteristic subject data was analyzed using chi square, while the MDA level result was analyzed using t-test (Mann-Whitney test). $\mathrm{p}<0.05$ was considered as significant.

\section{Results}

\section{Characteristic of subjects}

The average age of respondents was $27.5 \pm$ 5.61 years. Of 40 respondents, six respondents with preterm childbirth and one respondent with full-term childbirth were in the risk age category. Thirteen (65\%) high parity respondents (multipara and grande multipara) experienced preterm childbirth (Table 1). Chi-square test showed a significant difference between parity status and the incidence of preterm delivery $(p<0.05)$.

The characteristic of the education level was divided into three namely low education level (including not attending school and graduating from elementary school), medium education level (including graduating from junior high school and equivalent high school), and high education level (including graduating from college). In this study, $13(65 \%)$ of respondents had a medium level of education who experienced preterm birth $(p>0.05)$. It means that the level of education was not related to the incidence of preterm delivery in this study.

During pregnancy, there is no prohibition for a pregnant woman to work, as long as the work is not exhausting and the mother still has enough time to rest. In this study, the job status of the respondents was divided into two groups, working and not working (housewife). Results showed that the mother's employment status was not related to the incidence of preterm delivery ( $p>0.05$ ). In this study, 14 (70\%) respondents who experienced preterm labor having a history of childbirth without prior premature rupture of membranes (PROM) history. There was no relationship between preterm delivery and a history of PROM in this study ( $p>0.05)$ indicated that a history of labor with premature rupture of membranes was not a trigger for preterm labor in this study.

\section{Malondialdehyde level between preterm labor and full-term delivery}

Figure 1 showed differences of malondialdehyde level between preterm labor and full-term delivery. Average level of malondialdehyde in preterm labor was $3.6 \pm 0.42 \mathrm{nmol} / \mathrm{mL}$ and in full-term labor was $2.9 \pm 0.33 \mathrm{nmol} / \mathrm{mL}(\mathrm{p}<0.05)$. 


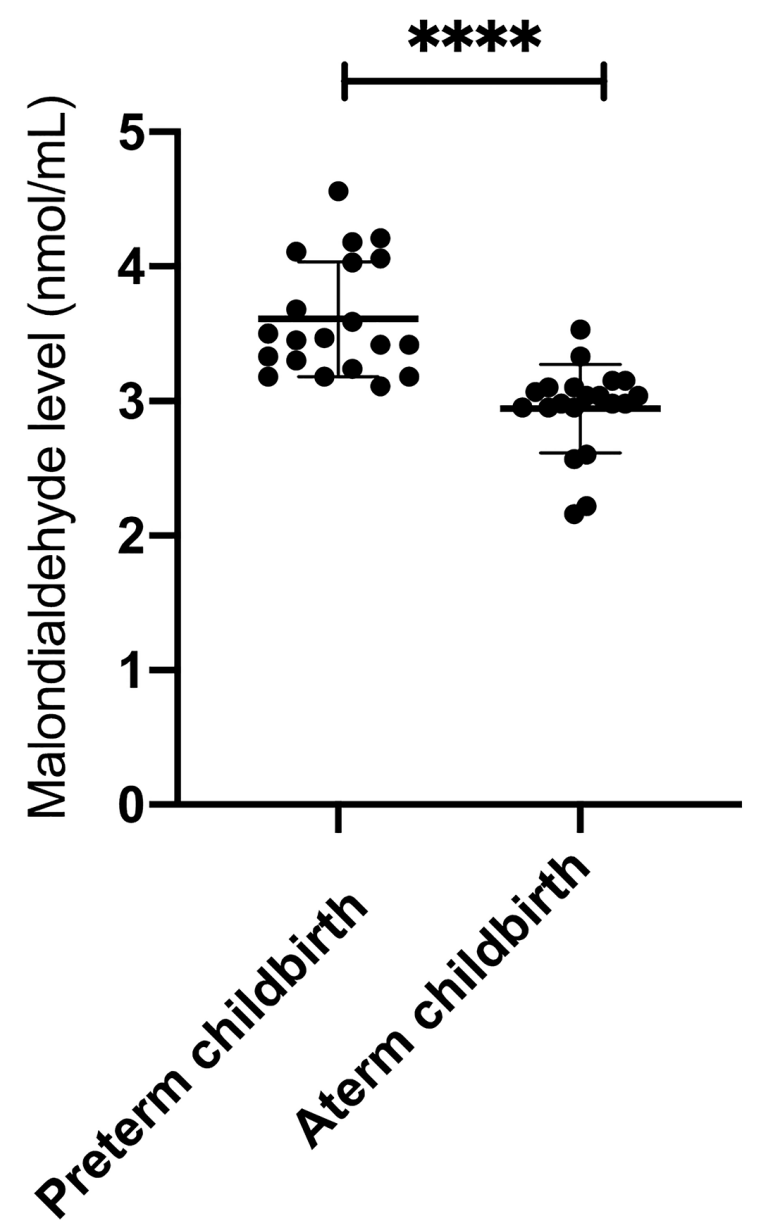

Figure 1. Differences in malondialdehyde levels in preterm labor and aterm childbirth

\section{Discussion}

Age is one of the risk factors that cause preterm childbirth, where it is considered risky if women are pregnant at below 20 years and more than 35 years. Pregnancy under the age of 20 is at risk because the uterus, pelvis, and reproductive organs have not fully developed properly. In addition, the strength of the perineum and abdominal muscles has not reached optimal conditions. Pregnancy over the age of 35 can lead to decreased endurance and setbacks. By the age of more than 35 years, endometrial fertility has worsened, which increase the chances of the mother giving birth to a baby with a congenital abnormality, thus affecting the health of the mother and the development of the fetus that is at risk of giving birth to premature babies $[16,17]$.
Primipara is a woman who has given birth to a premature or mature child for the first time. Multipara is a woman who has given birth to more than one child. Grande multipara is a woman who has given birth to 5 or more children. In this study, there was a relationship between parity and the incidence of preterm delivery $(p<0.05)$. Due to decreased fertility and increased antenatal risk, women who give birth more than once or high parity (multipara and grande multipara) have a higher risk of giving birth to premature babies.

The level of education was not related to the incidence of preterm delivery $(p>0.05)$. But, another study states that pregnant women without an education level of approximately 1.73 times are at risk than mothers with a diploma or higher degree because the higher social status is associated with better health status, namely because of social access through knowledge, money, power, social relations, prestige, provide access to health services [16]. During pregnancy, there is no prohibition for a pregnant woman to work, as long as the work is not exhausting and the mother still has enough time to rest. In this study, the mother's employment status was not related to the incidence of preterm delivery. The risk of preterm labor in women with a history of PROM at $<37$ weeks' gestation is $34-44 \%$, while the risk for experiencing PROM is around $16-32 \%$ [20]. However, a history of labor with premature rupture of membranes was not a trigger for preterm labor in this study.

The mechanism by which preterm labor occurs is not known. However, several factors that cause preterm labor include activation of the maternalfetal hypothalamic pituitary adrenal axis, infection, inflammation, decidual bleeding, as well as excessive uterine stretching, which are a series of clinical symptoms and synchronization between uterine muscle contractions (myometrium), tearing fetal germ (chorion and amnion), and cervical ripening. Myometrial smooth muscle contraction can also be triggered by an imbalance between ROS and antioxidants in the body that shifts towards an increase in ROS. Oxidative stress will increase 
lipid peroxidation. Lipid peroxidation will produce aldehyde compounds including MDA, which is the most stable product [17].

Our study showed a significant difference between malondialdehyde levels in preterm labor and full-term delivery $(\mathrm{p}<0.05)$. Oxidative stress arises due to an increase in metabolic activity which increases ROS production. Increased metabolic activity occurs from the development of the preimplantation embryo from the zygote to the formation of the blastocyst. In addition to an increase in metabolic activity, energy requirements also increase because the energy formation process is very close to the mitochondrial activity as an energy-generating organelle in cells so that mitochondrial disruption or damage can affect the process of energy-forming which is needed to provide the energy required for blastocyst implantation [18-20].

After the placenta is formed, increased metabolic activity in the mitochondria of the placenta still occurs because of the fetus that continues to develop in the uterus. The placenta contains many mitochondria which increase oxidative metabolism which produces superoxide anion which is one of the sources of ROS [21]. Furthermore, Martin (2018) reported that the level of oxidative stress in the mother during pregnancy varies because it is caused by an increase in oxidative stress in the placenta. Oxidative stress on the placenta is required for the developmental process by regulating trophoblast proliferation, differentiation, and invasion, promoting placental angiogenesis, as well as regulating autophagy and apoptosis for placentation. A high level of systemic oxidative stress in pregnant women is associated with preterm delivery. A result of high oxidative stress in pregnant women causes placental dysfunction or damage that leads to preterm delivery and can cause high levels of oxidative stress in premature newborns due to direct blood exchange in the placenta [22].

Sultana (2017) stated that high levels of MDA were caused by an increase in oxidative stress that occurred in the placenta. Increased metabolic activity in placental mitochondria and increased ROS production due to increased metabolic demands of the growing and developing fetus. Persistent and excessive oxidative stress causes a decrease in antioxidants and affects the antioxidant capacity of the placenta and the reducing system resulting in permanent changes in placental tissue. The placenta cannot meet the needs of the fetus and as a result, the survival of the fetus is disrupted so the fetus must be delivered [21].

Another impact of ROS is generated through oxidative stress, namely the activation of NF-kB and the expression of cyclooxygenase-2, which regulates the inflammatory pathway [23]. COX-2 will produce prostaglandins, then prostaglandins also increase the production of matrix metalloproteinase in the cervix and decidua to promote cervical ripening, decidua, and activation of the amniotic membrane. Prostaglandin F2 $\alpha$ binds to the F-prostanoid receptor to induce myometrial contractions so that labor begins [24].

In normal pregnancy, oxidative stress on the placenta is required to regulate trophoblast proliferation, differentiation, and invasion, support placental angiogenesis and regulate autophagy and apoptosis for placentation. Autophagy appears to be induced in the trophoblast early in pregnancy. Oxygen deficit evokes autophagy in human primary trophoblast cells. Autophagy also allows the recycling of nutrients to be reused in an energy-efficient manner. Under some conditions, autophagy can selectively degrade ROS inhibitors such as catalase, making it difficult to resist damage from oxidative stress. Apoptosis, or programmed cell death, is a physiological phenomenon in trophoblast turnover. Oxidative stress can induce apoptosis via external or intrinsic signals. Apoptosis and autophagy in the human trophoblast are interrelated pathways. Apoptosis and autophagy are homeostatic processes in trophoblast cells. Apoptosis and autophagy ensure normal cell turnover, and unwanted apoptosis can also induce protective autophagy [25].

Furthermore, a physiological balance between ROS and antioxidant activity can be maintained at full-term pregnancy. The formation of free radicals 
can increase during normal pregnancy, but because of the sufficient antioxidant capacity, it can prevent oxidative stress due to lipid peroxidation so that pregnancy can continue until gestational age at fullterm [25]. Ali et al (2014) reported that MDA is a biomarker of oxidative stress produced through the lipid peroxidation process. They found a decrease in the levels of enzymatic antioxidants (SOD and catalase) and an increase in lipid peroxidation (MDA) in preterm labor. MDA will increase if the body's antioxidants cannot cope with the increase in free radicals, resulting in oxidative stress [26].

A study on preterm labor divided the sample on preterm childbirth (divided into three groups) and full-term delivery (control group) showed that MDA levels as a lipid peroxidation biomarker for LBW preterm newborns were significantly higher $(\mathrm{p}<0.001)$. The total antioxidant status of LBW newborns was significantly lower $(\mathrm{p}<0.001)$. Malondialdehyde increases preterm delivery in LBW newborns accompanied by antioxidant deficiency [27]. The high levels of MDA are caused by an increase in oxidative stress that occurs in the placenta. As a result of high oxidative stress in pregnant women, dysfunction or damage to the placenta happens that causes preterm labor and can cause high levels of oxidative stress in premature newborns, which is caused by direct blood exchange across the placenta [22].

The current range of MDA in normal delivery or the range of MDA levels that do not induce preterm birth is not known with certainty. This study aims to determine the oxidative stress that occurs in preterm and full-term labor. For this reason, researchers have measured MDA levels as a marker of oxidative stress by comparing MDA levels in mothers with preterm delivery and mothers with full-term delivery. However, information regarding changes in placental oxidative stress during pregnancy is not well studied. In this study, placental MDA levels were determined as markers of lipid peroxidation and reactive oxygen species. A large number of antioxidants in the human body are present as micro- and macromolecules, and these molecules function synergistically in preventing oxidative stress. Therefore, further research could measure quantitative total antioxidant capacity and MDA simultaneously to observe antioxidant defenses.

\section{Conclusion}

In preterm childbirth, the mean level of MDA was higher than in full-term labor.

\section{Acknowledgment}

The authors would like to express gratitude toward Defrin, Rizanda Machmud, Dessy Arisanty for assisting this paper writing. We also would like to thank Gustina Lubis for the guidance. Finally, the authors would like to express gratitude to all members of the Biochemistry Laboratory for their kindness and assistance with this research.

\section{Author contribution}

Conceptualization, Y.M.S., E. Y.; Methodology, Y.M.S.; Investigation: Y.M.S.; Resources, Y. M.S.; Writing - Original Draft, Y.M.S.; Review: Y. M.S., E.Y.; Supervision, EY.

\section{Declaration of interest}

The authors declare no conflict of interest.

Received: 12 August 2021

Accepted: 17 September 2021

Published online: 12 November 2021

\section{References}

1. WHO | New global estimates on preterm birth published [Internet]. [cited 21 Oct 2021]. Available: https://www. who.int/reproductivehealth/global-estimates-pretermbirth/en/

2. Laporan Hasil Riset Kesehatan Dasar (Riskesdas) | Badan Penelitian dan Pengembangan Kesehatan [Internet]. [cited 21 Oct 2021]. Available: https://www.litbang.kemkes. go.id/laporan-riset-kesehatan-dasar-riskesdas/

3. Alamrani A, Mahmoud S, Alotaibi M. Intrauterine infection as a possible trigger for labor: the role of toll-like receptors and proinflammatory cytokines. Asian Biomedicine. 2015;

4. Catov JM, Nohr EA, Olsen J, Ness RB. Chronic hypertension related to risk for preterm and term small for gestational age births. Obstet Gynecol. 2008;112: 290-296. https:// doi.org/10.1097/AOG.0b013e31817f589b 
5. Agrawal V, Hirsch E. Intrauterine infection and preterm labor. Semin Fetal Neonatal Med. 2012;17: 12-19. https:// doi.org/10.1016/i.siny.2011.09.001

6. Onderdonk AB, Delaney ML, DuBois AM, Allred EN, Leviton A, Extremely Low Gestational Age Newborns (ELGAN) Study Investigators. Detection of bacteria in placental tissues obtained from extremely low gestational age neonates. Am J Obstet Gynecol. 2008;198: 110.e1-7. https://doi.org/10.1016/j.ajog.2007.05.044

7. Shynlova O, Lee Y-H, Srikhajon K, Lye SJ. Physiologic uterine inflammation and labor onset: integration of endocrine and mechanical signals. Reprod Sci. 2013;20: 154-167. https://doi.org/10.1177/1933719112446084

8. Lozovoy MAB, Simão ANC, Panis C, Rotter MAC, Reiche EMV, Morimoto HK, et al. Oxidative stress is associated with liver damage, inflammatory status, and corticosteroid therapy in patients with systemic lupus erythematosus. Lupus. 2011;20: 1250-1259. https:// doi.org/10.1177/0961203311411350

9. Tanhapour M, Vaisi-Raygani A, Bahrehmand F, Khazaei M, Kiani A, Rahimi Z, et al. Association between the cytotoxic T-lymphocyte antigen-4 mutations and the susceptibility to systemic lupus erythematosus; Contribution markers of inflammation and oxidative stress. Cell Mol Biol (Noisy-le-grand). 2016;62: 56-61. doi:10.14715/cmb/2016.62.12.10

10. Hardt U, Larsson A, Gunnarsson I, Clancy RM, Petri M, Buyon JP, et al. Autoimmune reactivity to malondialdehyde adducts in systemic lupus erythematosus is associated with disease activity and nephritis. Arthritis Res Ther. 2018;20: 36. https://doi.org/10.1186/s13075-018-1530-2

11. Ramana KV, Srivastava S, Singhal SS. Lipid peroxidation products in human health and disease 2014. Oxid Med Cell Longev. 2014;2014: 162414. https://doi. org/10.1155/2014/162414

12. Shah D, Mahajan N, Sah S, Nath SK, Paudyal B. Oxidative stress and its biomarkers in systemic lupus erythematosus. J Biomed Sci. 2014;21: 23. https://doi.org/10.1186/14230127-21-23

13. Sangeetha Lakshmi B, Harini Devi N, Suchitra MM, Srinivasa Rao PVLN, Siva Kumar V. Changes in the inflammatory and oxidative stress markers during a single hemodialysis session in patients with chronic kidney disease. Ren Fail. 2018;40: 534-540. https://doi.org/10.1080/0886 022X.2018.1487857

14. Ayala A, Muñoz MF, Argüelles S. Lipid peroxidation: production, metabolism, and signaling mechanisms of malondialdehyde and 4-hydroxy-2-nonenal. Oxid Med Cell Longev. 2014;2014: 360438. https://doi. org/10.1155/2014/360438

15. Mihailovič M, Cvetkovč M, Ljubič A, Kosanovič M, Nedeljkovič $\mathrm{S}$, Jovanovič I, et al. Selenium and malondialdehyde content and glutathione peroxidase activity in maternal and umbilical cord blood and amniotic fluid. Biol Trace Elem Res. 2000;73: 47-54. https://doi.org/10.1385/BTER:73:1:47
16. El-Sayed AM, Galea S. Temporal changes in socioeconomic influences on health: maternal education and preterm birth. Am J Public Health. 2012;102: 1715-1721. https:// doi.org/10.2105/AJPH.2011.300564

17. Slavić M, Appiah I, Nikolić-Kokić A, Radojicić R, Jones $\mathrm{DR}$, Spasić MB, et al. The anti-oxidative defence system in the isolated rat uterus during spontaneous rhythmic activity. Acta Physiol Hung. 2006;93: 335-339. https:// doi.org/10.1556/APhysiol.93.2006.4.9

18. Acton BM, Jurisicova A, Jurisica I, Casper RF. Alterations in mitochondrial membrane potential during preimplantation stages of mouse and human embryo development. Mol Hum Reprod. 2004;10: 23-32. https://doi.org/10.1093/ molehr/gah004

19. Ludwig TE, Squirrell JM, Palmenberg AC, Bavister BD. Relationship between development, metabolism, and mitochondrial organization in 2-cell hamster embryos in the presence of low levels of phosphate. Biol Reprod. 2001;65: 1648-1654. https://doi.org/10.1095/ biolreprod65.6.1648

20. Trimarchi JR, Liu L, Porterfield DM, Smith PJ, Keefe DL. Oxidative phosphorylation-dependent and -independent oxygen consumption by individual preimplantation mouse embryos. Biol Reprod. 2000;62: 1866-1874. https:// doi.org/10.1095/biolreprod62.6.1866

21. Sultana Z, Maiti K, Aitken J, Morris J, Dedman L, Smith R. Oxidative stress, placental ageing-related pathologies and adverse pregnancy outcomes. Am J Reprod Immunol. 2017;77. https://doi.org/10.1111/aji.12653

22. Martin A, Faes C, Debevec T, Rytz C, Millet G, Pialoux $\mathrm{V}$. Preterm birth and oxidative stress: Effects of acute physical exercise and hypoxia physiological responses. Redox Biol. 2018;17: 315-322. https://doi.org/10.1016/j. redox.2018.04.022

23. Aponte A, Agarwal A. Premature rupture of membranes and oxidative stress. In: Agarwal A, Aziz N, Rizk B, editors. Studies on women's health. Totowa, NJ: Humana Press; 2013. pp. 143-147. https://doi.org/10.1007/9781-62703-041-0 8

24. Institute of Medicine. Preterm Birth: Causes, Consequences, and Prevention. Behrman RE, Butler AS, editors. Washington (DC): National Academies Press (US); 2007. https://doi.org/10.17226/11622

25. Wu F, Tian F-J, Lin Y. Oxidative stress in placenta: health and diseases. Biomed Res Int. 2015;2015: 293271. https://doi.org/10.1155/2015/293271

26. Ali ME, Rahman MM, Sarkar SM, Hamid SBA. Heterogeneous metal catalysts for oxidation reactions. J Nanomater. 2014;2014: 1-23. https://doi.org/10.1155/2014/192038

27. Negi R, Pande D, Kumar A, Khanna RS, Khanna HD. In vivo oxidative DNA damage and lipid peroxidation as a biomarker of oxidative stress in preterm low-birthweight infants. J Trop Pediatr. 2012;58: 326-328. https://doi. org/10.1093/tropej/fmr078 